\title{
Potencial e avaliação de uma aplicação PPSIG sobre a orla do Guaíba em Porto Alegre
}

\author{
Potential and evaluation of a PPGIS application about the \\ Guaíba's waterfront in Porto Alegre
}

\section{Geisa Tamara Bugs \\ Antônio Tarcísio da Luz Reis}

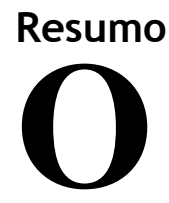

objetivo deste artigo é testar, na realidade brasileira, o potencial da participação pública com sistemas de informação geográfica (PPSIG) para identificar as percepções dos participantes quanto às preferências, aos usos futuros, à acessibilidade e às melhorias a serem realizadas, hipoteticamente, na Orla do Guaíba em Porto Alegre, RS.

Adicionalmente, a PPSIG é avaliada por esses participantes. A PPSIG possibilita que o público produza dados espaciais que representam a sua percepção do ambiente em questão. A metodologia inclui a utilização do SoftGIS, desenvolvido na Finlândia e customizado para o presente experimento através de uma interface do tipo faça você mesmo. A amostra total foi de 156 participantes que utilizaram o mapa on-line interativo, marcando 3.366 lugares válidos. Destes, 109 avaliaram a PPSIG. A análise dos dados espaciais se baseou na agregação espacial para delinear áreas de concentração, através dos mapas de calor. Os dados do questionário de avaliação da PPSIG Orla do Guaíba foram analisados conforme as frequências das respostas com relação às categorias consideradas em cada variável. Os resultados evidenciam o potencial da PPSIG para identificar as percepções dos participantes, assim como a sua avaliação satisfatória, não tendo sido encontradas maiores dificuldades para sua utilização.

Palavras-chaves: Potencial da PPSIG. Avaliação da PPSIG. PPSIG na Orla do Guaíba. Tecnologias da informação e comunicação (TIC). Sistemas de Informação Geográfica (SIG).

\begin{abstract}
The purpose of this study is to test, in the Brazilian context, the potential of Public Participation Geographic Information Systems (PPSIG) to identify participants' perceptions as to the preferences, future uses, accessibility and improvements to be carried out, hypothetically, on the Guaíba Waterfront, in Porto Alegre/RS.

Additionally, the participants evaluated the PPSIG. The PPSIG allows people to produce spatial data that represents their perception of the considered environment. The methodology includes the use of SoftGIS developed in Finland and customized for the experiment on the Guaiba Waterfront, through a kind of do-it-yourself interface. The total sample consisted of 156 participants using the interactive online map, scoring 3,366 valid places. 109 of those participants also evaluated the PPSIG. The data analysis is based on spatial aggregation to delineate areas of concentration through heat maps. The questionnaire data about the assessment of the Guaiba Waterfront PPSIG were analysed according to the frequency of responses regarding the categories considered in each variable. The results show the potential of the PPSIG to identify the perceptions of participants, as well as its satisfactory assessment, with no greater difficulties found for its use.
\end{abstract}

Antônio Tarcísio da Luz Reis Universidade Federal do Rio Grande

Porto Alegre - RS - Brasil

Geisa Tamara Bugs Universidade Feevale

Recebido em 12/04/16 Aceito em 22/07/16
Keywords: PPGIS potential. PPGIS evaluation. Guaíba waterfront PPGIS. Information and communication technology (ICT). Geographic information systems (GIS). 


\section{Introdução}

Nas últimas décadas, o desenvolvimento das tecnologias da informação e comunicação (TIC), a partir da emergência das tecnologias digitais, mudou nossos padrões de comportamento, e, principalmente, de comunicação (LÉVY, 1993; DI FELICE, 2007). A chamada revolução digital tem contribuído para projetar a civilização em direção à era da informação, caracterizada pela adoção em massa dessas tecnologias em todas as esferas de nossas vidas (CASTELLS, 1996). Sobretudo com a difusão da Web, a comunicação, que costumava ser predominantemente unidirecional, passou a ser caracterizada pela capacidade de envio de mensagens a partir de muitos para muitos de maneira assíncrona (DI FELICE, 2007). Esses novos sistemas de comunicação reformularam e potencializaram os processos de obtenção, sistematização, representação e construção da informação e do conhecimento (LÉVY, 1993; DI FELICE, 2007). Recentemente, a Web adquiriu características mais interativas, passando a ser conhecida como Web 2.0 (O'REILLY, 2007). Enquanto a Web 1.0 dizia respeito à implantação e popularização da rede, a Web 2.0 caracteriza-se pelos mecanismos de busca e sítios de colaboração (DÁVILA, 2007). Nos blogues, por exemplo, o usuário faz postagens e outros usuários podem comentá-las, o que não ocorria nos primórdios da Web. Conforme Batty et al. (2010), a Web 2.0 se caracteriza por conteúdos gerados pelos usuários, com aproveitamento da sabedoria das multidões, criação de dados numa escala sem precedentes, colaboração, efeitos de rede, e abertura.

A Web 2.0 também teve impactos transformadores na natureza dos sistemas de informação geográfica (SIG) e em questões de produção e uso da informação geográfica (HALL et al., 2010), as quais se tornaram mais abertas e acessíveis ao público em geral (BATTY et al., 2010). Os serviços de mapas on-line, por exemplo, são utilizados por uma variedade de sítios Web para explorar o mapeamento voluntário e combinar a funcionalidade de um site com a de outro, isto é, criar mashups (misturar conteúdo de mais de uma fonte para criar um novo serviço completo) de mapas (HUDSON-SMITH; CROOKS, 2008). Diferentemente do passado, quando as instituições eram as principais responsáveis pela criação e distribuição de informações geoespaciais, agora qualquer pessoa pode facilmente produzir um mapa e publicá-lo on-line. Nesse contexto, mesmo que involuntariamente, está ocorrendo um aumento da consciência da informação geográfica pelo público em geral. Segundo Hudson-Smith e Crooks (2008), esse fenômeno pode ser considerado uma revolução no mundo das informações geográficas, pois possibilita que ferramentas SIG possam ser aprendidas rápida e eficazmente sem haver a necessidade de imersão em atividades profissionais.

Logo, as tecnologias digitais estão mudando também as formas de relação das pessoas com o ambiente em que vivem (PEREIRA; FLORENTINO; ROCHA, 2013). A ubiquidade das TIC está produzindo ambientes urbanos que são completamente diferentes de tudo o que se experimentou até agora, gerando um novo contexto no qual um grupo muito maior de cidadãos pode se engajar (ROCHA; PEREIRA, 2011). Os serviços de mapas on-line, por sua vez, expandem os limites da compreensão desse ambiente, o que possibilita o aumento do interesse e da capacidade dos habitantes em participar das decisões que afetam o seu espaço de vivência.

Métodos tradicionais de participação não podem ser desprezados, mas quando se considera a internet, imagina-se ser possível contornar alguns dos problemas citados pela literatura. Exemplificando, para Innes e Booher (2004) as audiências públicas, método comumente aplicado em diversos contextos, raramente alteram decisões prévias de órgãos e agentes públicos, antagonizam os membros do público e polarizam as questões em pauta. Mesmo em um país com diferenças socioeconômicas como o Brasil, a internet vem se consolidando como um poderoso meio de comunicação, visto que o número de smartphones com acesso à internet e à banda larga tem crescido, fazendo parte, inclusive, de políticas públicas de desoneração de impostos (MINISTÉRIO..., 2013). Também é crescente o número de iniciativas visando a disponibilização de informações públicas em portais na internet, como o SOS Mata Atlântica (2015), e de iniciativas de ativismo online oriundas da sociedade civil, como o Cidade Democrática (2013).

Nesse sentido, a participação pública no planejamento urbano é valorizada por gerar confiança e comprometimento para alcançar resultados tangíveis (STERN; GUDES; SVORAY, 2009), reconhecer o valor e incorporar o conhecimento de diferentes atores (BRABHAM, 2009), introduzir ideias inovadoras (CARVER, 2001), e melhorar e legitimar decisões (INNES; BOOHER, 2004), dentre outros aspectos. Além disso, uma das liberdades fundamentais em uma sociedade democrática é o direito dos cidadãos de conhecer e participar das decisões que afetam o seu bem-estar e o lugar em que vivem (BRINK et al., 2007). No Brasil, o debate a respeito da participação pública no planejamento urbano 
ganhou amplo destaque após a aprovação do Estatuto da Cidade, que delineia regras gerais para a participação pública e introduz instrumentos com o objetivo de ampliar a participação do público em processos de planejamento e gestão do espaço urbano (BRASIL, 2001). Mas apesar das legislações pró-participação, a literatura (por exemplo: Villaça (2005)) aponta que boa parte dos supostos benefícios não estão sendo atingidos. É necessário qualificar os processos participativos. As características heterogêneas da população envolvida exigem técnicas e metodologias que criem as condições para o debate consistente.

Todavia, envolver o público no planejamento urbano não é uma tarefa simples e direta. Nas palavras de Forester (2006, p. 447):

Fácil de pregar, mas difícil de praticar, participação pública eficaz no planejamento e na gestão pública exige sensibilidade e técnica, imaginação e coragem.

De tal modo que ainda não se conseguiu abordar a perspectiva da população de forma consistente no planejamento urbano (KAHILA; KYTTÄ, 2009). A literatura destaca, por exemplo, que há grande dificuldade em se passar de um sistema de planejamento dominado por especialistas para um que daria voz a diferentes interessados (WALLIN; HORELLI, 2012), e que o planejamento urbano, em geral, utiliza somente dados oficiais, nos quais as pessoas são levadas em consideração apenas na forma de estatísticas agregadas (BRABHAM, 2009). O planejamento urbano, em tese, sempre foi baseado na coleta e troca de informações entre diferentes partes interessadas, e uma mudança no modelo informacional tem, invariavelmente, impacto significativo em como se faz todo o processo (HALLER; HÖFFKEN, 2010). Ferramentas digitais estão se tornando onipresentes na vida cotidiana e possuem alto potencial para coleta de dados socioespaciais $\mathrm{e}$ temporais, o que é completamente diferente dos modelos estáticos de coleta de dados que o planejamento urbano comumente utiliza (BRABHAM, 2009; BATTY et al., 2012). Assim, para que o planejamento urbano acompanhe as mudanças tecnológicas se faz obrigatório adicionar novas ferramentas, que permitam exibir e gerenciar novos fluxos de informações (PEREIRA; FLORENTINO; ROCHA, 2013).

Nesse contexto, distintos autores afirmam que a PPSIG possui potencial para aprimorar a participação (KAHILA, 2008; KINGSTON, 2011). A PPSIG, como o próprio nome sugere, utiliza ferramentas SIG para a participação, conectando a capacidade técnica dos SIG ao conhecimento local
(SIEBER, 2006). De acordo com Kahila (2008), com a PPSIG combinam-se três aspectos fundamentais: interação, tecnologia e espacialização do conhecimento local. No início dos anos 2000 a PPSIG chegou a ser considerada uma evolução dos métodos clássicos de participação (CARVER, 2001). Mas o entusiasmo inicial começou a diminuir por volta de 2005 (POPLIN, 2012). Vários problemas foram levantados, tais como a complexidade das aplicações, a demasiada preocupação com o desenvolvimento de plataformas cada vez mais tecnológicas, e o distanciamento das iniciativas acadêmicas das práticas no "mundo real" (NYERGES et al., 2006). Houve também reconhecimento de que termos e conceitos como "participação" e "empoderamento" foram utilizados de forma acrítica (HALL et al., 2010). Então, quase que concomitante, os mashups de mapas e o mapeamento colaborativo emergiram na Web 2.0 e rapidamente repercutiram na literatura. Logo surgiram experiências de PPSIG tirando partido dos mapas on-line interativos e do aumento da consciência da informação geográfica pelo público (HALL et al., 2010). Esses projetos demonstraram crescente interesse dos cidadãos em usar as ferramentas de participação baseadas em mapas on-line (POPLIN, 2012), renovando o interesse pela PPSIG. Conforme Brovelli, Minghini e Zamboni (2014), as melhores condições para a realização de projetos de PPSIG surgiram cerca de dez anos após a PPSIG ter sido considerada uma evolução dos métodos clássicos de participação (CARVER, 2001), com o advento da Web 2.0 e sua abordagem bidirecional, tendo como base os conteúdos gerados pelos usuários. Contudo, as inovações técnicas em aplicações PPSIG requerem novas experiências empíricas a fim de verificar a sua adequação para a efetiva participação de parte das pessoas.

Ademais, a maioria das experiências existentes foi desenvolvida fora do Brasil, por geógrafos, com foco na produção de cartografia participativa, ou por profissionais da tecnologia da informação, com foco no desenvolvimento tecnológico dos projetos (NYERGES et al., 2006). Ainda é bastante comum os SIG serem vistos apenas como uma ferramenta técnica e, portanto, com foco apenas no seu desenvolvimento técnico (DRAGIĆEVIĆ; BALRAM, 2004). Logo, é importante aprofundar o conhecimento sobre o uso da PPSIG (NYERGES et al., 2006), incluindo a identificação das percepções de seus participantes sobre ela. Assim sendo, o objetivo deste estudo é testar, na realidade brasileira, o potencial da PPSIG para identificar as percepções dos participantes quanto a preferências, usos futuro, acessibilidade e melhorias a serem 
realizadas, hipoteticamente, na Orla do Guaíba em Porto Alegre, RS. Adicionalmente, a aplicação da PPSIG é avaliada por esses mesmos participantes.

\section{Metodologia}

A metodologia inclui a utilização do SoftGIS, desenvolvido na Finlândia e customizado para o experimento sobre a Orla do Guaíba, aqui denominado PPSIG Orla do Guaíba, por meio de uma interface do tipo faça você mesmo. Esse tipo de interface permite que qualquer pessoa, mesmo sem conhecimento de programação, consiga construir uma aplicação Web, através de mecanismos drag-and-drop (arrastar e largar) (Figura 1). O SoftGIS já foi aplicado em mais de vinte cidades, em diversos países (ver lista em Brown e Kyttä (2014)), de modo que é possível atestar sua confiabilidade. Ele pode ser definido como uma metodologia para a coleta da percepção dos habitantes sobre o ambiente (KAHILA; KYTTÄ, 2009). Trata-se de um questionário baseado em um mapa interativo, isto é, os usuários respondem a questões marcando pontos, linhas ou polígonos no mapa on-line.

A PPSIG Orla do Guaíba possibilitou a coleta de informações sobre as percepções de moradores de
Porto Alegre quanto à qualidade dos espaços da Orla, no trecho compreendido entre a Usina do Gasômetro e a Vila Assunção (Figura 2), haja vista o desejo e a necessidade de revitalização dessa área urbana e a falta de conhecimento estabelecido sobre a percepção dos seus usuários. A aplicação da PPSIG Orla do Guaíba estava composta de nove páginas, conforme segue:

(a) a primeira apresentava a ferramenta, orientava e convidava o respondente a participar;

(b) a segunda continha questões de caracterização dos participantes (por exemplo: idade e renda);

(c) as cinco seguintes continham 12 questões associadas ao uso do mapa on-line interativo, que previam a marcação de locais (por exemplo: "Quais locais deveriam ter acesso exclusivo para pedestres?") e que estavam categorizadas em quatro temas (preferências; usos futuros; acessibilidade; e melhorias);

(d) a penúltima continha o questionário de avaliação da PPSIG; e

(e) a última página continha o fechamento e agradecimento.

Figura 1 - Interface do-it yourself do SoftGIS para criar nova página (esquerda) e adicionar pop-up (direita)
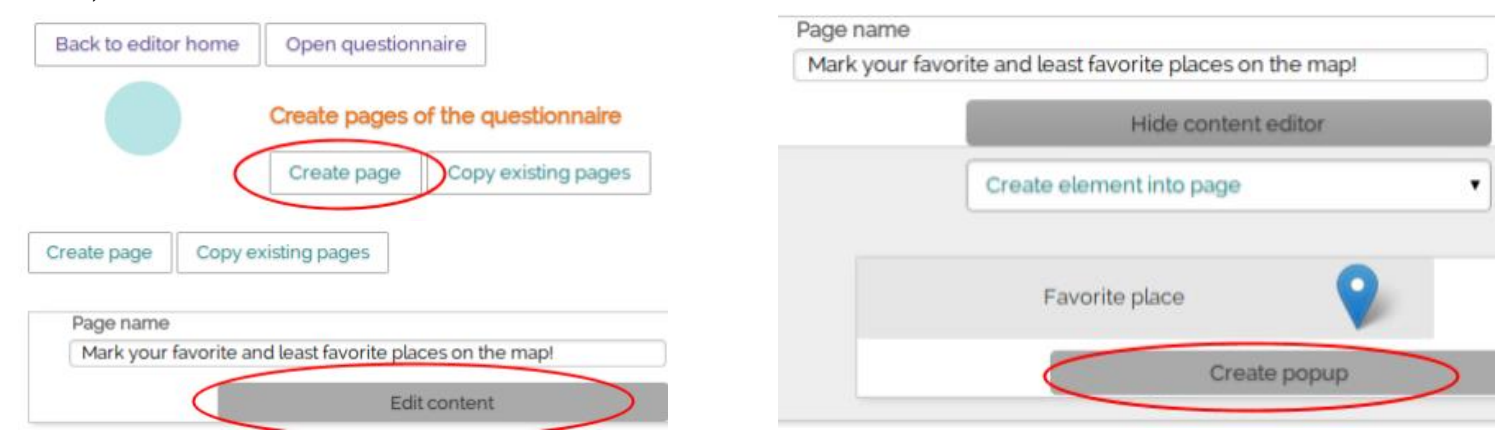

Fonte: Mapita (2014).

Figura 2 - Página inicial da PPSIG Orla do Guaíba

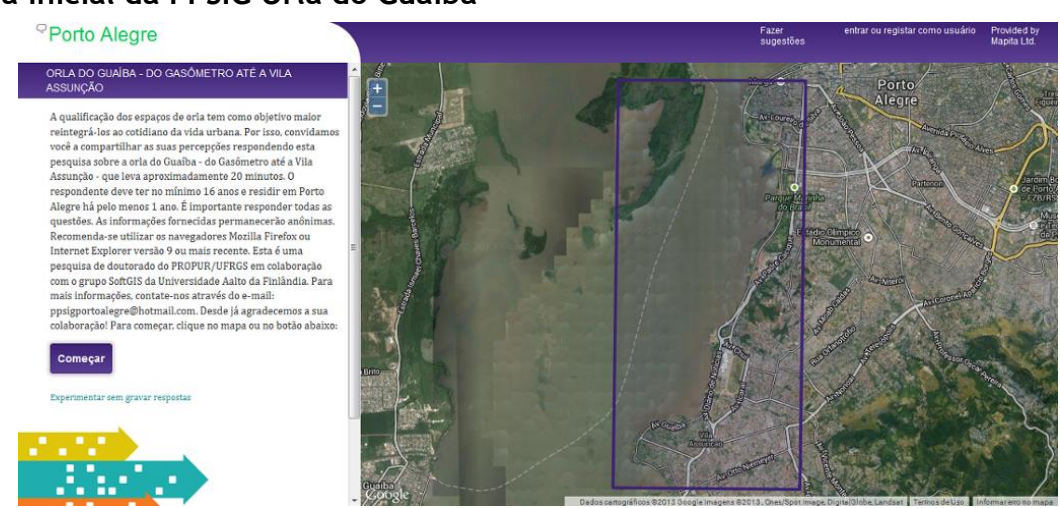

Fonte: Bugs (2014). 
O questionário de avaliação da PPSIG foi elaborado essencialmente com questões fechadas para identificar a frequência das respostas em relação às seguintes afirmações/perguntas:

(f) me senti colaborando para o futuro da cidade;

(g) em geral como você avalia esta ferramenta de participação?; e

(h) comparativamente aos métodos participativos mais convencionais como você avalia esta ferramenta?

A PPSIG Orla do Guaíba foi divulgada nas redes sociais e em grupos de discussão sobre Porto Alegre durante o mês de dezembro de 2013. Assim, a amostra de participantes é aleatória, sem controle e, logo, sem o estabelecimento de uma taxa de retorno. As únicas restrições, informadas na tela de apresentação da PPSIG eram de que o respondente deveria ter no mínimo 16 anos (maioridade eleitoral) e residir em Porto Alegre há pelo menos um ano. A amostra total foi de 156 participantes que utilizaram o mapa on-line interativo, marcando 3.366 lugares válidos no mapa. Destes, 109 fizeram a avaliação da PPSIG. Sumariamente, a maioria possui idade entre $26 \mathrm{e}$ 40 anos $(59,8 \%)$, predominam aqueles com renda de 5 a 10 salários mínimos (34,9\%) e com formação universitária $(96,3 \%)$ (Tabela 1). Esse perfil é similar ao de outros estudos envolvendo PPSIG, como o de Poplin (2012). Além disso, o perfil dos participantes da PPSIG Orla do Guaíba diz respeito a uma porção da população que não participa de canais presenciais de participação, como o Orçamento Participativo (OP) da Prefeitura Municipal de Porto Alegre, no qual há predominância do nível de renda até dois salários mínimos e de pessoas com ensino fundamental (FEDOZZI et al., 2013), corroborando o apontado por Stern, Gudes e Svoray (2009) sobre o fato de os participantes na Web diferirem daqueles dos encontros presenciais.
Os dados espaciais coletados foram manipulados, analisados e representados espacialmente em software de SIG (ArcGIS e QGIS). O objetivo dessa análise espacial é mensurar propriedades e relacionamentos, levando em conta a localização espacial do fenômeno em estudo (CÂMARA et al., 2002). Os procedimentos incluíram a análise exploratória e a visualização de dados, através da criação de mapas, o que permite descrever a distribuição das variáveis de estudo, e identificar a existência de padrões na distribuição espacial (CÂMARA et al., 2002). A maioria das perguntas previa a marcação de pontos no mapa. No caso da análise de padrões de pontos, o objeto de interesse é a própria localização dos eventos (CÂMARA et al., 2002). Quando se utiliza o ponto, de certa forma assume-se que cada ponto representa uma área poligonal, mas com forma e tamanho desconhecidos (BROWN, 2012). Um participante pode fazer referência a uma área espacial do tamanho de um campo de futebol, enquanto outro pode fazer referência a uma área espacial tão grande quanto um bairro, por exemplo. Assim, a análise dos dados se baseou na agregação espacial dos pontos para delinear áreas de concentração, por meio dos mapas de calor. Os dados do questionário de avaliação da aplicação PPSIG Orla do Guaíba foram analisados conforme as frequências das respostas com relação às categorias consideradas em cada variável.

\section{Resultados}

Conforme os objetivos deste artigo, são apresentados a seguir os resultados acerca do potencial da PPSIG para identificar as percepções dos participantes quanto a preferências, usos futuros, acessibilidade e melhorias a serem realizadas, hipoteticamente, na Orla do Guaíba em Porto Alegre, RS, assim como a avaliação, por parte desses participantes, da aplicação PPSIG Orla do Guaíba.

Tabela 1 - Características dos participantes

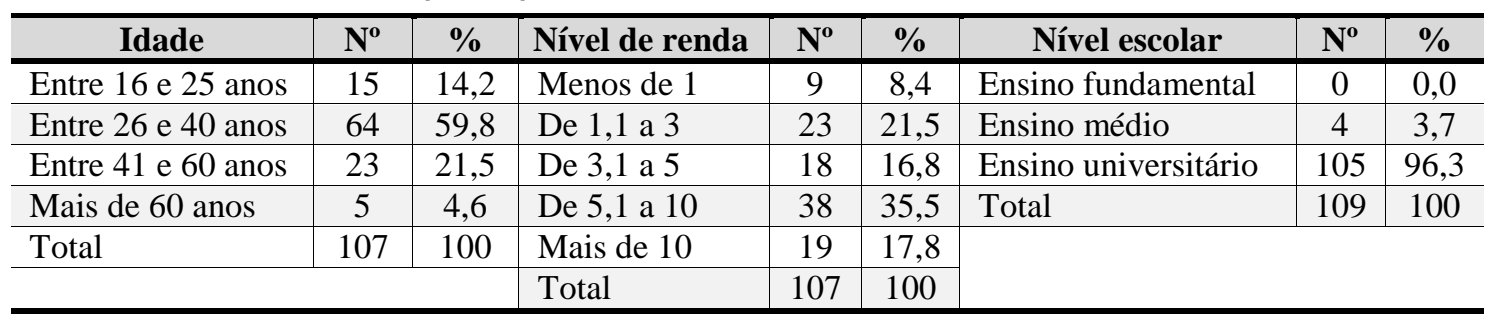

Nota: o universo total de participantes que avaliaram a PPSIG Orla do Guaíba é 109, mas algumas questões não foram respondidas por todos. 


\section{Potencial da PPSIG para identificar as percepções dos participantes}

\section{Identificação das preferências}

A identificação das preferências foi realizada por meio da marcação pelos participantes dos lugares de que mais gostavam e daqueles de que menos gostavam (Figura 3). Foi feita uma interpolação dos pontos marcados como lugares de que "mais gosto" (vermelho) e de que "menos gosto" (verde), para gerar uma ideia de continuidade do conjunto de pontos e facilitar a visualização de concentrações de respostas semelhantes. A análise visual do mapa permite destacar como áreas de que 'mais gosto' as próximas aos seguintes pontos de referência: Usina do Gasômetro, Parque Maurício Sirotsky Sobrinho, Parque Marinha do Brasil, Museu Iberê Camargo, Veleiros do Sul, e Associação dos Auditores do Estado, ao passo que se destacam como áreas de que 'menos gosto' as próximas aos seguintes pontos de referência: Anfiteatro Pôr-do-Sol/Foz do Arroio Dilúvio, Sport Clube Internacional/Largo D. Vicente Scherer, Estaleiro Só/Barra Shopping Sul, e Vila dos Pescadores.
As principais razões apontadas pelos usuários para gostar de cada lugar foram (Tabela 2 e Figura 4):

(a) Usina do Gasômetro - contemplação das visuais (21\% - 62 de 295);

(b) Parque Maurício Sirotsky Sobrinho contemplação das visuais (19,5\% - 24 de 123);

(c) Parque Marinha do Brasil - contemplação das visuais e contato com a natureza $(15 \%$ - 23 de 151 LMM, cada);

(d) Museu Iberê Camargo - contemplação da visuais $(31 \%$ - 32 de 104) e visita a espaços culturais (25\% - 26 de 104);

(e) Veleiros do Sul - contemplação das visuais $(23,5 \%$ - 8 de 34$)$ e contato com a natureza $(18 \%$ 6 de 34); e

(f) Associação dos Auditores do Estado contemplação das visuais $(27 \%$ - 19 de 71$)$ e aparência positiva dos espaços abertos (18\% - 13 de 71).

A razão mais vezes indicada para gostar do lugar é a contemplação das visuais (21,6\% - 168 de 778), evidenciando a importância da existência de lugares junto à Orla do Guaíba que possibilitem a contemplação das visuais.

Figura 3 - Lugares de que "mais gosto" e de que "menos gosto"

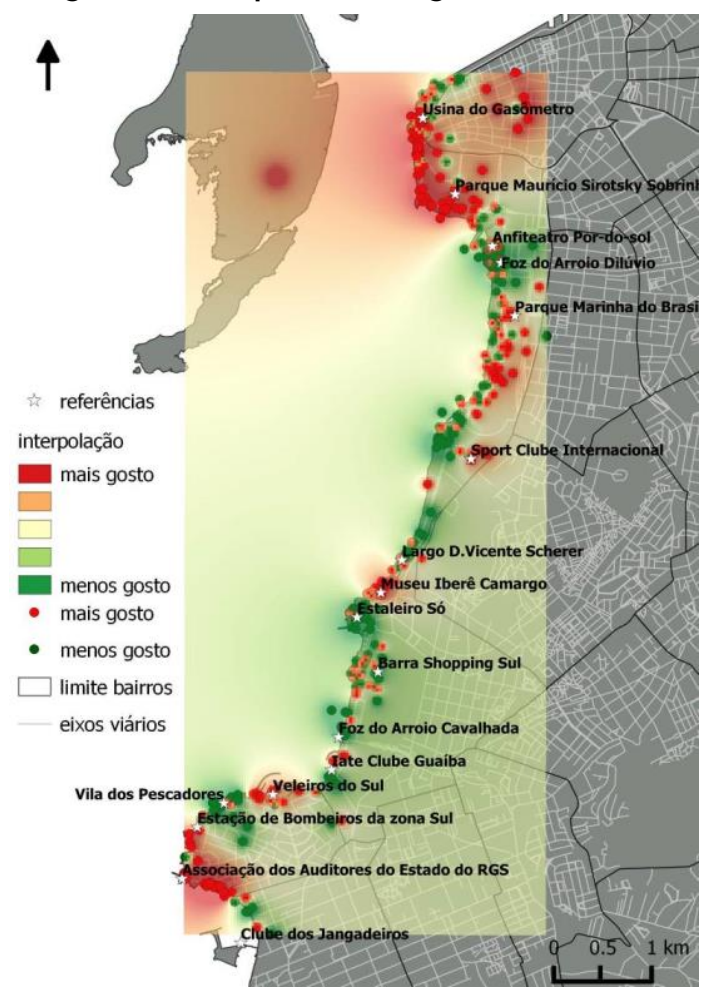

Nota: representação dos pontos e da superfície interpolada. 
Tabela 2 - Principais razões para gostar da Orla por número de pontos marcados

\begin{tabular}{l|c|c|c|c|c|c|c|c}
\hline $\begin{array}{c}\text { Ponto de } \\
\text { referência/ } \\
\text { Razão }\end{array}$ & $\begin{array}{c}\text { Usina do } \\
\text { Gasômetro }\end{array}$ & $\begin{array}{c}\text { Parque } \\
\text { Maurício } \\
\text { Sirotsky } \\
\text { Sobrinho }\end{array}$ & $\begin{array}{c}\text { Parque } \\
\text { Marinha } \\
\text { do Brasil }\end{array}$ & $\begin{array}{c}\text { Museu } \\
\text { Iberê } \\
\text { Camargo }\end{array}$ & $\begin{array}{c}\text { Veleiros } \\
\text { do Sul }\end{array}$ & $\begin{array}{c}\text { Associação } \\
\text { dos } \\
\text { Auditores } \\
\text { do RGS }\end{array}$ & $\begin{array}{c}\mathbf{N}^{\mathbf{o}} \\
\text { Total }\end{array}$ & $\begin{array}{c}\text { \% } \\
\text { Total }\end{array}$ \\
\hline Visuais & 62 & 24 & 23 & 32 & 8 & 19 & 168 & 21,6 \\
Aparência & 30 & 12 & 20 & 13 & 5 & 13 & 93 & 12,0 \\
Natureza & 30 & 14 & 23 & 8 & 6 & 11 & 92 & 11,8 \\
Lazer & 33 & 17 & 18 & 8 & 2 & 11 & 89 & 11,4 \\
Caminhar & 35 & 16 & 21 & 4 & 3 & 4 & 83 & 10,7 \\
Ciclismo & 25 & 14 & 16 & 7 & 0 & 4 & 66 & 8,5 \\
Memórias & 23 & 10 & 18 & 6 & 3 & 7 & 67 & 8,6 \\
Cultural & 29 & 3 & 1 & 26 & 0 & 1 & 60 & 7,7 \\
Esportes & 16 & 10 & 10 & 0 & 4 & 1 & 41 & 5,3 \\
Velejar & 12 & 3 & 1 & 0 & 3 & 0 & 19 & 2,4 \\
$\mathbf{N}^{\circ}$ Total & 295 & 123 & 151 & 104 & 34 & 71 & 778 & 100,0 \\
\% Total & 37,9 & 15,8 & 19,4 & 13,4 & 4,4 & 9,1 & 100,0 & \\
\hline & & & & & & & \\
\hline
\end{tabular}

Figura 4 - Principais razões para gostar da Orla

Principais razões para gostar

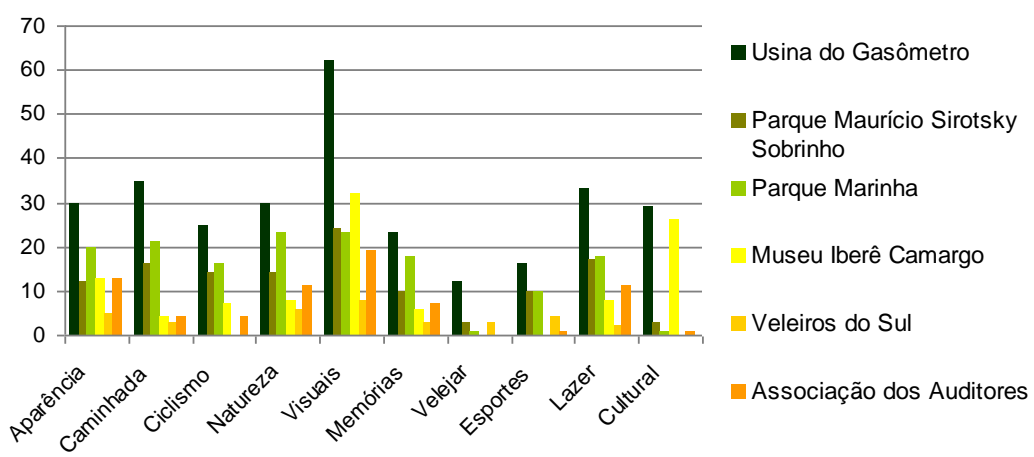

As principais razões apontadas pelos usuários para não gostar de cada lugar foram (Tabela 3 e Figura 5):

(a) Anfiteatro Pôr-do-Sol/Foz do Arroio Dilúvio aparência negativa dos espaços abertos $(24 \%$ - 35 de 144) e lixo (24\% - 35 de 144);

(b) Sport Clube Internacional/Largo D. Vicente Scherer - aparência negativa dos espaços abertos (16\% - 10 de 61$)$ e falta de manutenção $(16 \%-10$ de 61);

(c) Estaleiro Só/Barra Shopping Sul - aparência negativa dos espaços abertos $(21,5 \%$ - 33 de 153$)$ e falta de manutenção (18\% - 27 de 153); e

(d) Vila dos Pescadores - aparência negativa dos espaços abertos (23\% - 10 de 43$)$ e insegurança quanto ao trânsito (23\% - 10 de 43).

A razão mais vezes citada para não gostar do lugar foi a sua aparência negativa $(21,9 \%$ - 88 de 401), indicando claramente a necessidade de requalificação estética desses espaços.

\section{Identificação dos usos futuros}

A identificação dos usos futuros foi realizada através da marcação no mapa dos principais usos desejados para este trecho de Orla no futuro, nomeadamente (Tabela 4):

(a) contemplação das visuais $(12,4 \%-173$ de 1.391); esportivo (11,7\% - 163 de 1.391);

(b) bares e restaurantes (10,9\% - 151 de 1.391); e

(c) lazer passivo - por exemplo: roda de chimarrão (10,4\% - 144 de 1.391).

O mapa de calor foi usado para identificar grupos com uma elevada concentração de pontos, para cada um dos quatro usos futuros mais vezes citados (Figura 6).

Através da análise visual dos mapas, percebe-se que os pontos marcados para o uso futuro de contemplação das visuais (Figura 6, mapa (a)) se concentram nas áreas próximas à Usina do Gasômetro, Parque Maurício Sirotsky Sobrinho, e Estaleiro Só. O uso esportivo (Figura 6, mapa (b)) se concentra na Usina do Gasômetro, Anfiteatro 
Pôr-do-Sol, e Estaleiro Só. Os bares e restaurantes (Figura 6, mapa (c)) se concentram na Usina do Gasômetro e Estaleiro Só; e o lazer passivo (Figura 6, mapa (d)) configura faixas lineares entre a Usina do Gasômetro e o Parque Maurício Sirotsky Sobrinho, e entre o Anfiteatro Pôr-do-sol e o Sport Clube Internacional, bem como concentrações pontuais no Estaleiro Só e na Vila Assunção. Assim, entende-se que ações futuras de planejamento urbano deveriam fomentar a contemplação de visuais, o uso esportivo, a instalação de bares e restaurantes e o lazer passivo levando em consideração as áreas indicadas pelos participantes.

Tabela 3 - Principais razões para não gostar da Orla por pontos marcados

\begin{tabular}{l|c|c|c|c|c|c}
\hline $\begin{array}{c}\text { Ponto de } \\
\text { referência/ } \\
\text { Razão }\end{array}$ & $\begin{array}{c}\text { Anfiteatro/ } \\
\text { Foz do } \\
\text { Dilúvio }\end{array}$ & $\begin{array}{c}\text { Internacional/ } \\
\text { Largo. D. } \\
\text { Vicente Scherer }\end{array}$ & $\begin{array}{c}\text { Estaleiro Só/ } \\
\text { Barra } \\
\text { Shopping Sul }\end{array}$ & $\begin{array}{c}\text { Vila dos } \\
\text { Pescadores }\end{array}$ & No Total & \% Total \\
\hline Aparência & 35 & 10 & 33 & 10 & 88 & 21,9 \\
Manutenção & 29 & 10 & 27 & 4 & 70 & 17,5 \\
Lixo & 35 & 8 & 16 & 0 & 59 & 14,7 \\
Acesso & 11 & 8 & 23 & 9 & 51 & 12,7 \\
Crime & 23 & 9 & 12 & 3 & 47 & 11,7 \\
Trânsito & 10 & 7 & 19 & 10 & 46 & 11,5 \\
Uso privado & 1 & 9 & 153 & 43 & 40 & 10,0 \\
No Total & 144 & 61 & 38,2 & 10,7 & 100,0 & 100,0 \\
\% Total & 35,9 & 15,2 & &
\end{tabular}

Figura 5 - Principais razões para não gostar da Orla

Principais razões para não gostar

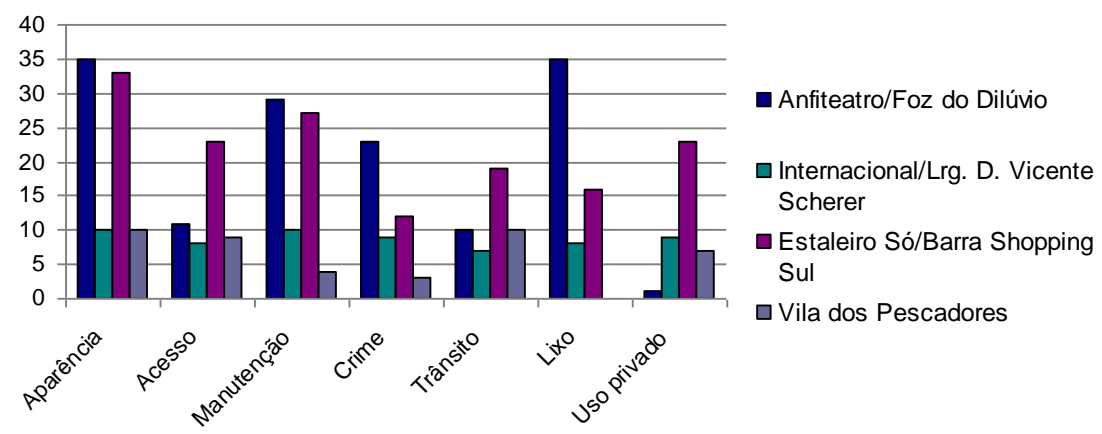

Tabela 4 - Usos futuros por número de pontos marcados

\begin{tabular}{l|c|c}
\hline \multicolumn{1}{c|}{ Uso futuro } & $\mathbf{N}^{\mathbf{0}}$ & $\mathbf{\%}$ \\
\hline Contemplação das visuais & 173 & 12,4 \\
Esportivo & 163 & 11,7 \\
Bares e restaurantes & 151 & 10,9 \\
Lazer passivo & 144 & 10,4 \\
Parque urbano & 136 & 9,8 \\
Espaços culturais & 124 & 8,9 \\
Área de proteção ambiental & 112 & 8,1 \\
Turístico & 110 & 7,9 \\
Passeios de barco & 99 & 7,1 \\
Banho/nado & 93 & 6,7 \\
Comércio ligado ao lazer & 56 & 4,0 \\
Residencial & 30 & 2,2 \\
Total de pontos marcados & 1391 & 100,0 \\
\hline
\end{tabular}

132 Bugs, G. T.; Reis, A. T. 
Figura 6 - Mosaico dos usos futuro mais vezes citados

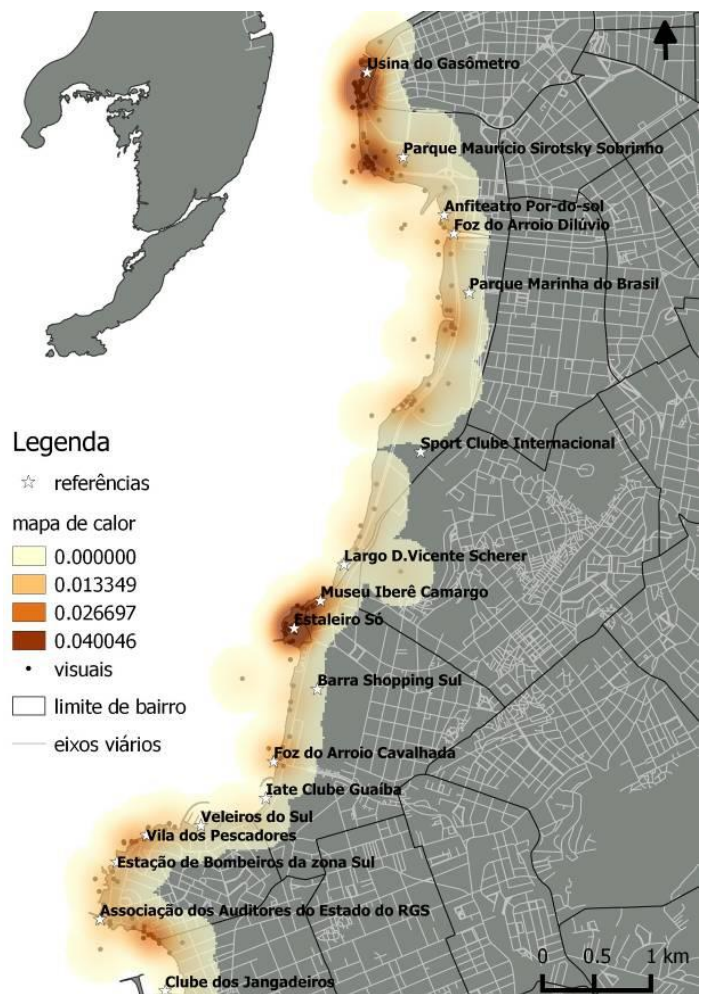

(a) Contemplação das visuais
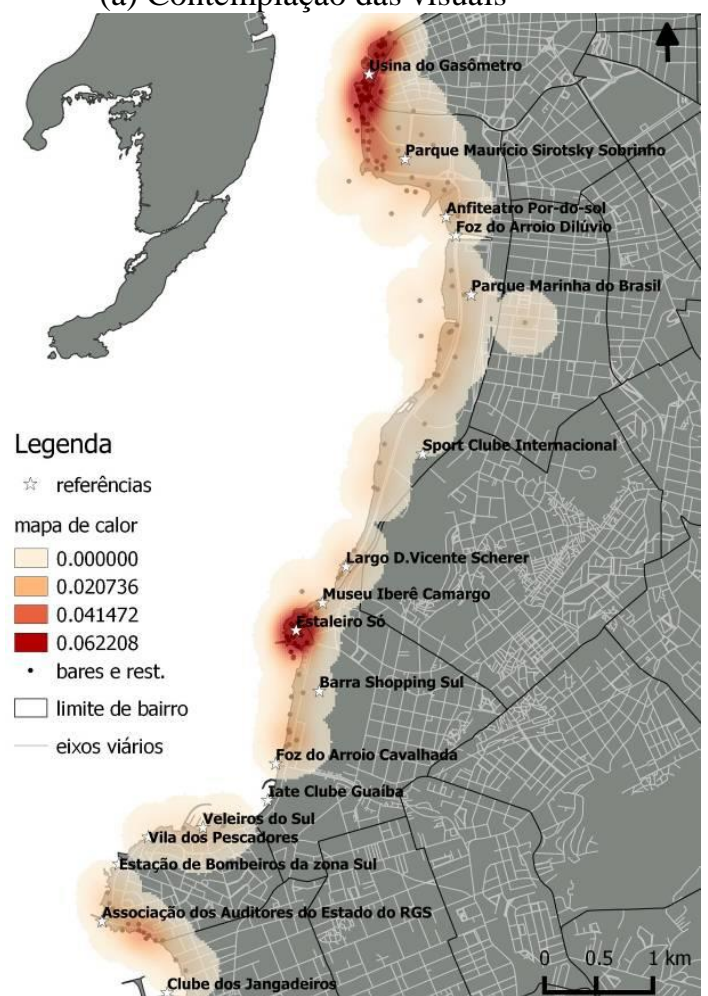

(c) Bares e restaurantes
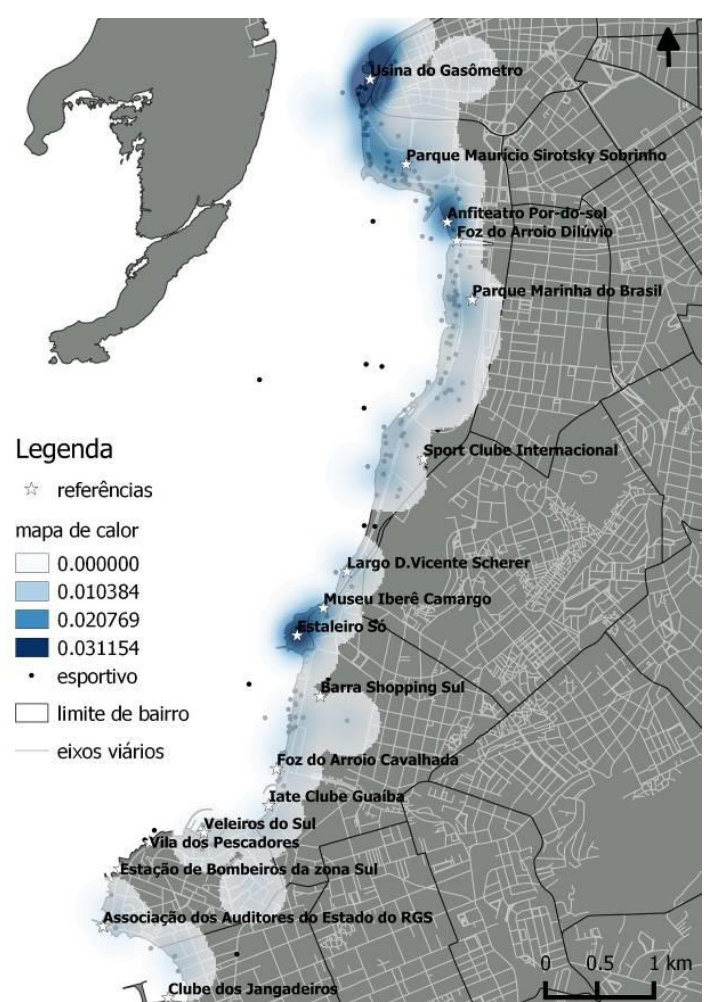

(b) Esportivo
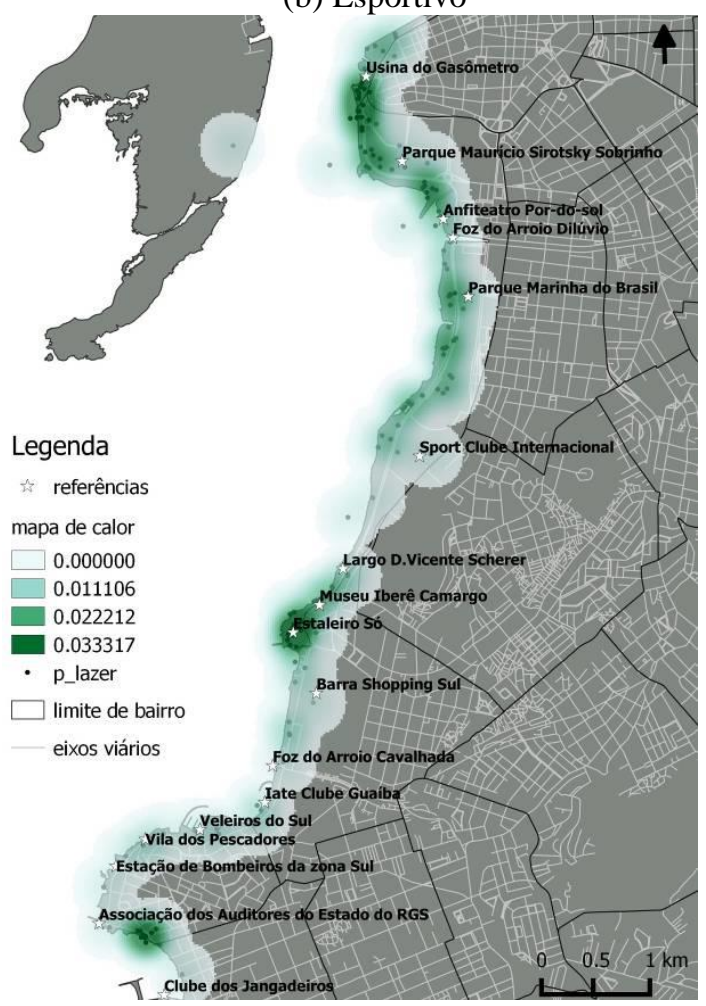

(d) Lazer passivo

Nota: o valor é maior na localização do ponto e diminui com o aumento da distância, podendo chegar a zero, ou seja, valores maiores representam maior densidade do fenômeno. 


\section{Acessibilidade}

A identificação da acessibilidade foi realizada através da marcação no mapa dos locais que deveriam ter acesso exclusivo para pedestres, daqueles que deveriam prever caminhos para pedestres, que deveriam ter ciclovias, e daqueles que deveriam prever vias de circulação contínua de veículos junto à Orla. O objetivo da análise visual, mais uma vez, foi mostrar onde ocorrem concentrações de pontos e/ou linhas, ou seja, onde houve maior incidência de respostas comuns. Os pontos marcados como locais de acesso exclusivo para pedestres (Figura 7, mapa (a)) se concentram nas proximidades da Usina do Gasômetro, entre o Parque Maurício Sirotsky Sobrinho e o Anfiteatro Pôr-do-Sol, no Parque Marinha do Brasil, e no Estaleiro Só, o que significa dizer que, segundo os participantes, nesses locais não deveria ser permitido o acesso de veículos, que ocorre atualmente em quase todos esses locais.

Já os caminhos para pedestres (Figura 7, mapa (b)) devem ser previstos em toda a extensão da Orla, conforme mostra a sobreposição das linhas desenhadas pelos participantes. O mapa (c) da Figura 7 apresenta como pano de fundo a camada das ciclovias existentes, em azul escuro, segundo o Cycle Map do Open Street Maps. Percebe-se que as ciclovias desenhadas pelos participantes (na cor rosa) se sobrepõem às existentes (na cor azul), bem como se estendem por toda a Orla e nas ruas adjacentes. Logo, pode-se afirmar que há uma ampla demanda pela ampliação das ciclovias nesse trecho da Orla. Cabe esclarecer que as linhas retas desenhadas da Usina do Gasômetro até a Vila
Assunção foram interpretadas como um indicativo de que toda a Orla deveria prever ciclovias, assumindo-se que esses usuários optaram por não marcar os pontos intermediários necessários para mudar de direção durante o desenho das linhas (Figura 7, mapa (b)). Por fim, o mapa das vias de circulação contínua de veículos (Figura 7, mapa (d)) apresenta o mapa do Open Street Maps como pano de fundo. Percebe-se que as linhas marcadas pelos participantes, em geral, correspondem exatamente às atuais avenidas Beira-Rio e Padre Cacique. Portanto, não há demandas futuras significativas no sentido de modificar o traçado viário existente.

\section{Melhorias}

A identificação das principais melhorias necessárias para qualificar a Orla na opinião dos participantes foram marcadas no mapa, conforme segue:
(a) iluminação (20,6\% - 207 de 1.007);
(b) limpeza/manutenção (15,8\% - 159 de 1.007);
(c) sanitário público (15,5\% - 156 de 1.007); $\mathrm{e}$
(d) mobiliário (13,4\% - 135 de 1.007) (Tabela 5).

Observa-se que os pontos marcados para as quatro melhorias tendem a se concentrar na Usina do Gasômetro, Anfiteatro Pôr-do-Sol e Estaleiro Só (Figura 8). Logo, verifica-se que tais melhorias revelam aspectos básicos de espaços abertos qualificados e que já deveriam estar presentes na Orla do Guaíba.

Tabela 5 - Melhorias

\begin{tabular}{lcc}
\hline \multicolumn{1}{c}{ Melhoria } & $\mathbf{N}^{\mathbf{0}}$ & $\mathbf{\%}$ \\
\hline Iluminação & 207 & 20,6 \\
\hline Limpeza/manutenção & 159 & 15,8 \\
\hline Sanitário público & 156 & 15,5 \\
\hline Mobiliário & 135 & 13,4 \\
\hline Equipamento esportivo & 82 & 8,1 \\
\hline Estacionamento & 71 & 7,1 \\
\hline Píer/atracadouro de barcos & 71 & 7,1 \\
\hline Gramado & 64 & 6,4 \\
\hline Marina pública & 62 & 6,2 \\
\hline Total & 1.007 & 100,0 \\
\hline
\end{tabular}

134 Bugs, G. T.; Reis, A. T. 
Figura 7 - Mosaico dos mapas para o tema acessibilidade

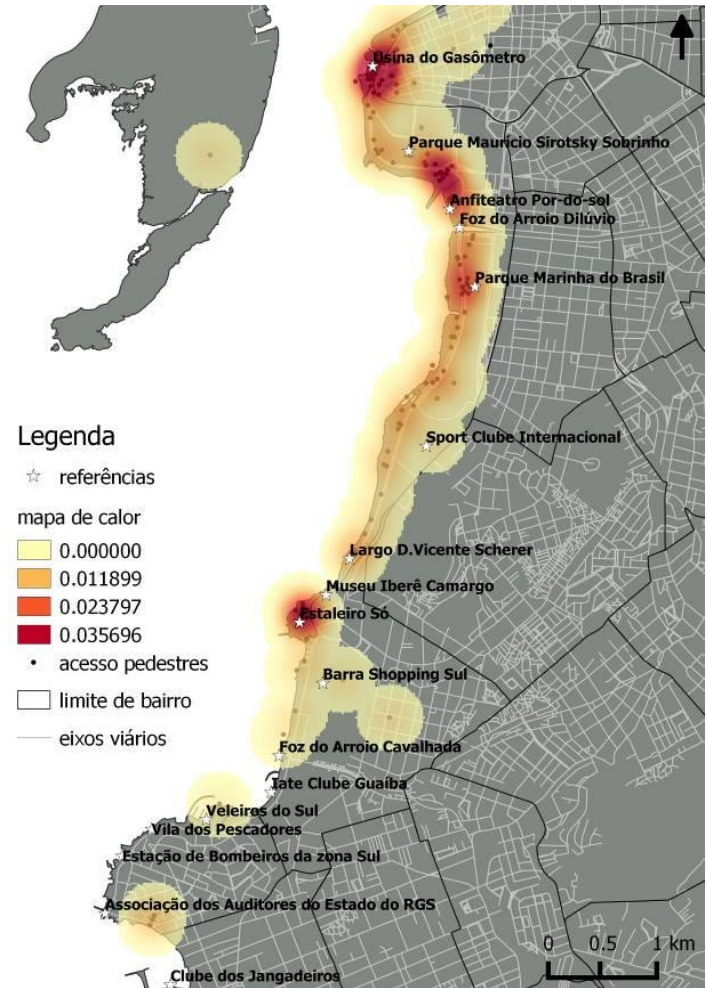

(a) Acesso exclusivo pedestres

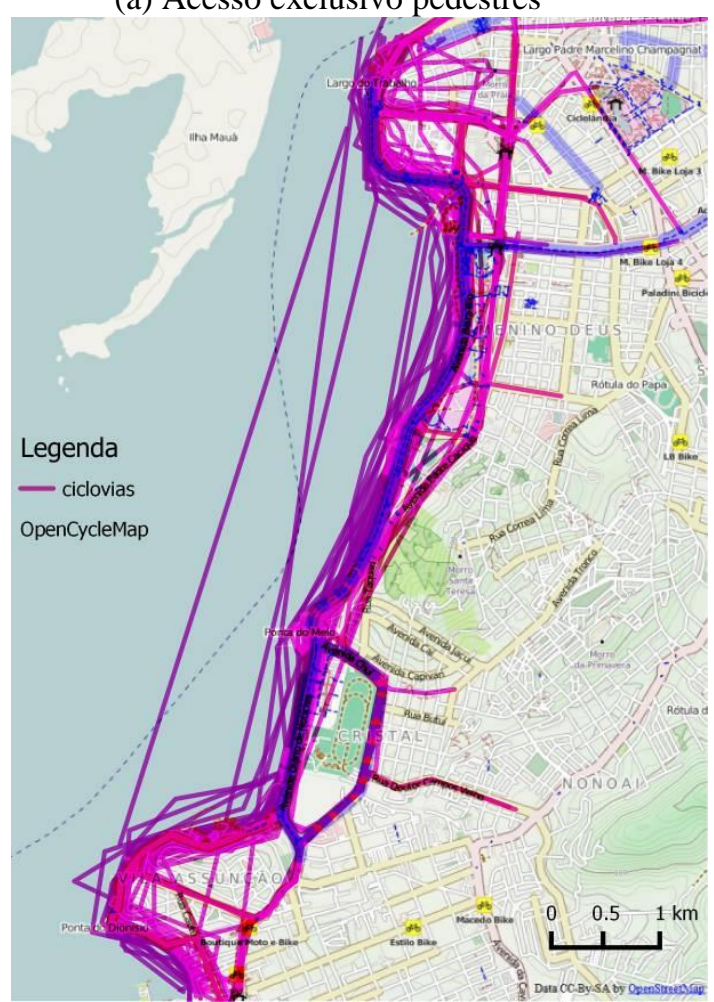

(c) Ciclovias

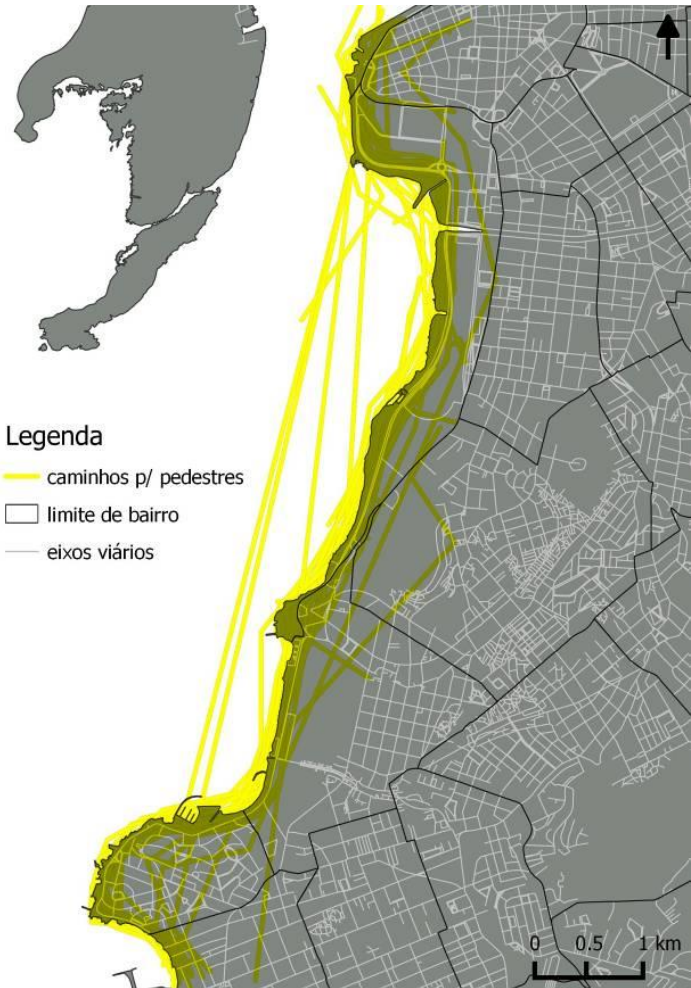

(b) Caminhos para pedestres

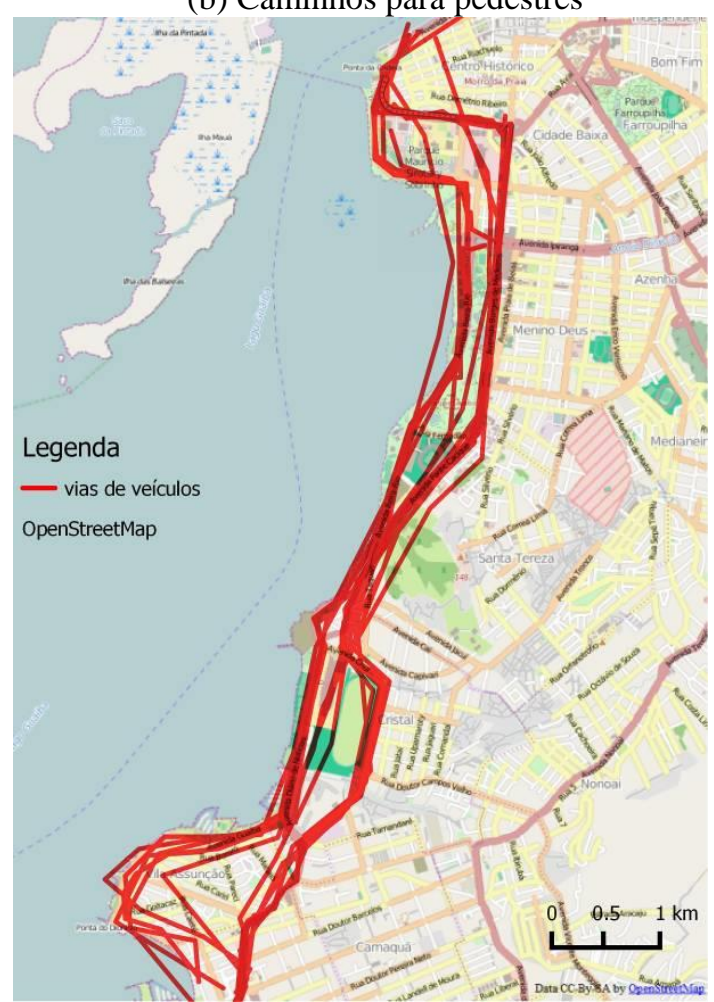

(d) Vias de circulação continua de veículos

Nota: no mapa (a) o valor é maior na localização do ponto e diminui com o aumento da distância, podendo chegar a zero, ou seja, valores maiores representam maior densidade do fenômeno. Nos mapas B e C há linhas desenhadas sobre a água, o que pode sugerir dificuldade de uso da ferramenta para desenhar linhas. 
Figura 8 - Mosaico das melhorias mais vezes citadas

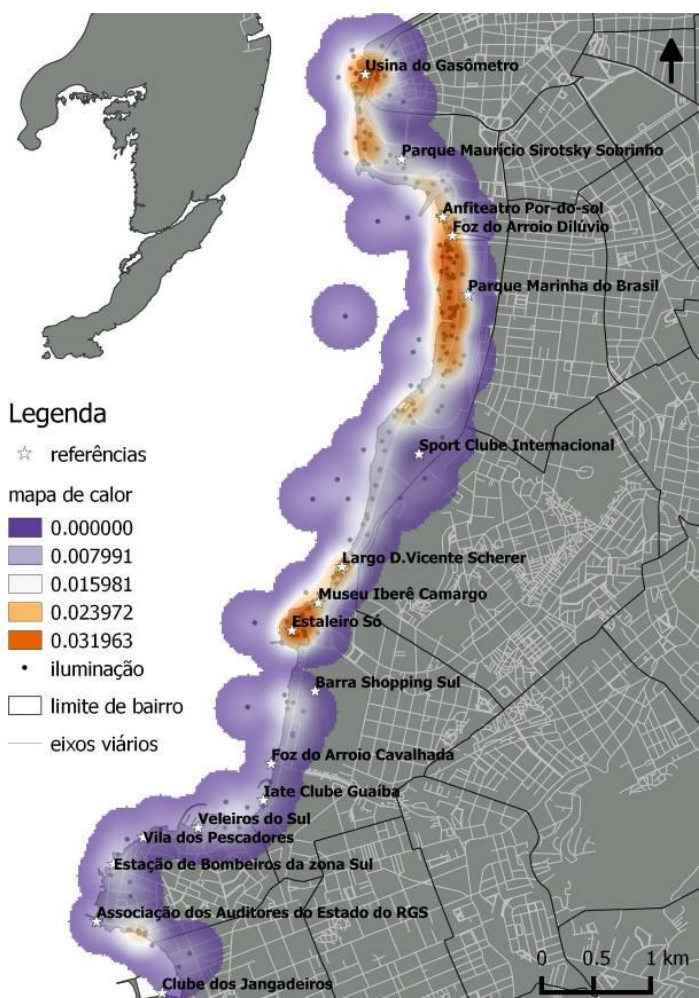

(a) Iluminação

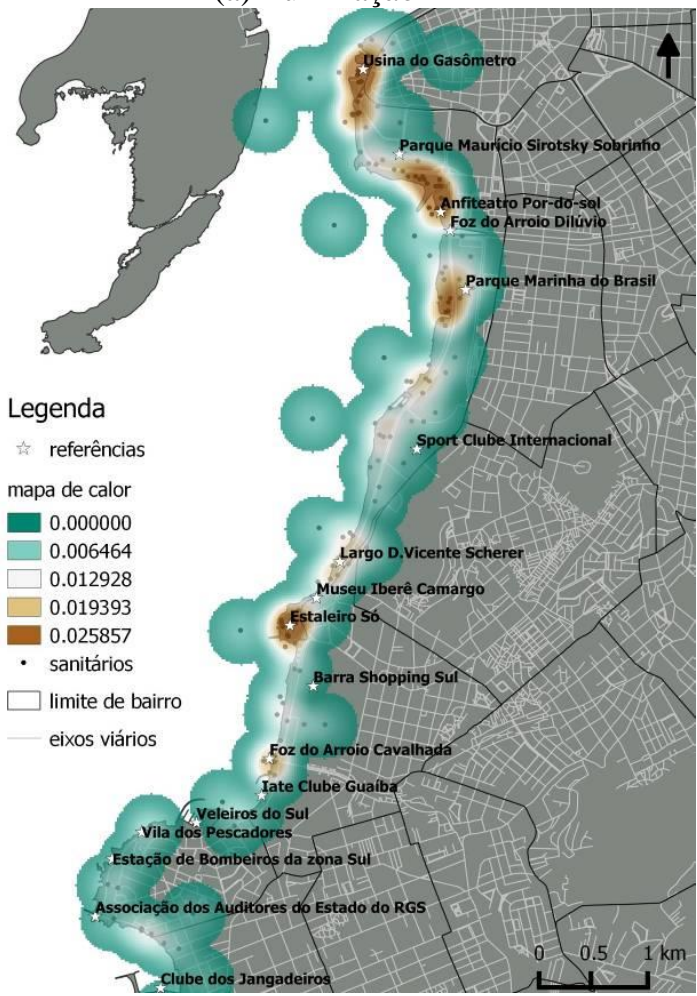

(c) Sanitário público

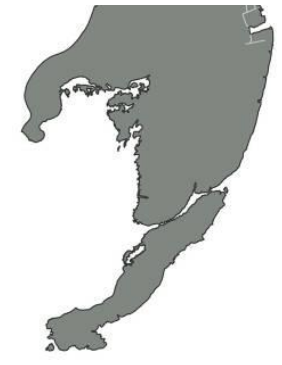

Legenda

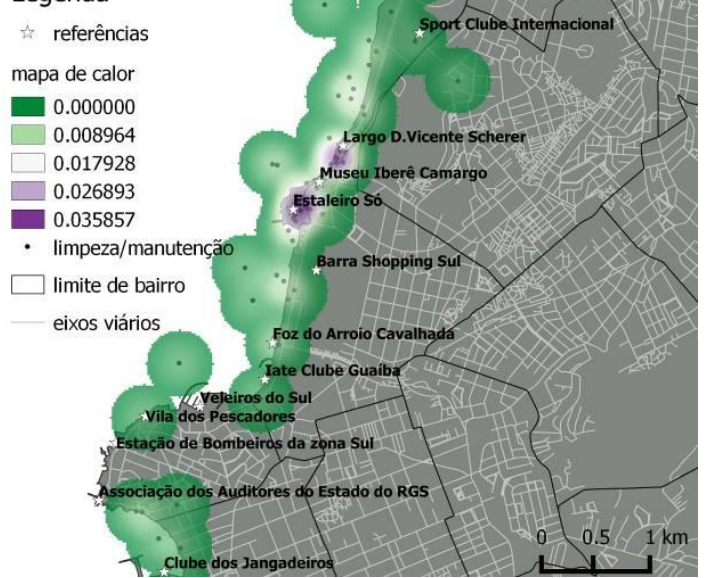

(b) Limpeza/manutenção
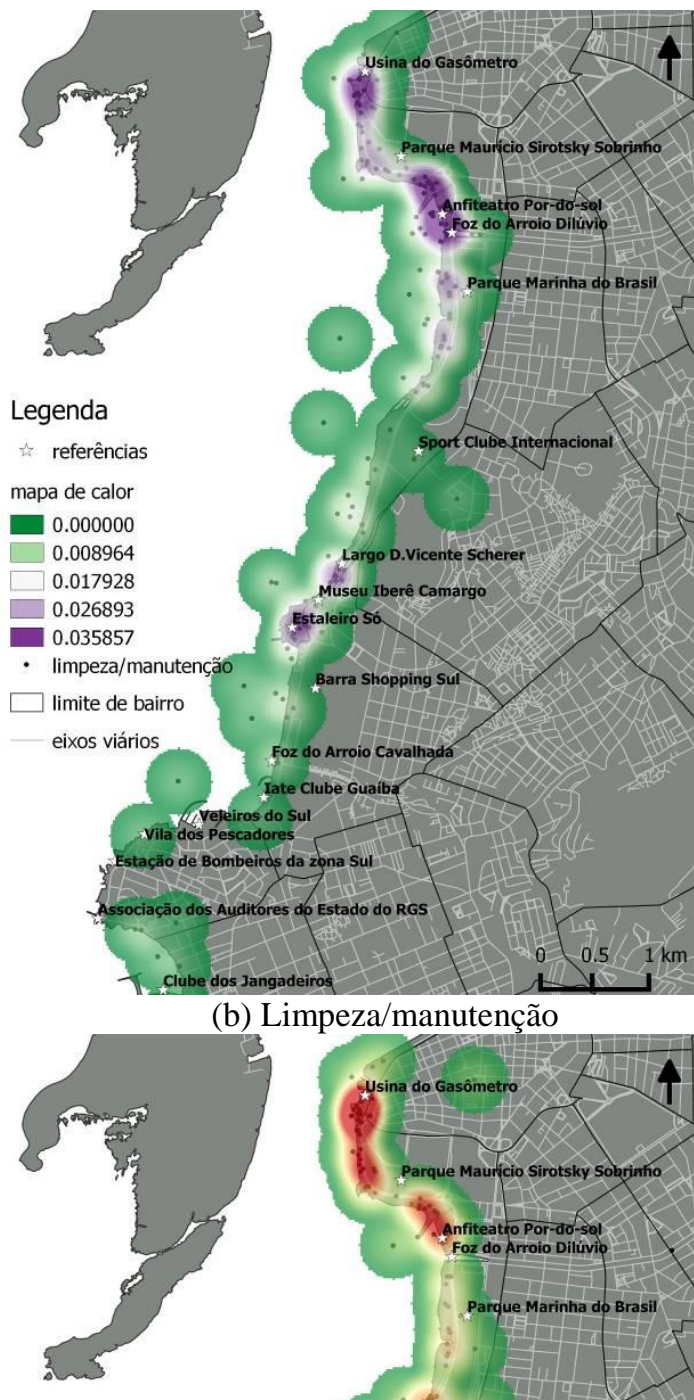

Legenda

thr referências

mapa de calor

0.000000

0.006068

0.012137
0.018205

0.018205
0.024274

- mobiliário

$\square$ limite de bairro

eixos viários

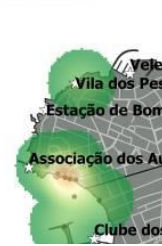

(d) Mobiliário

Nota: o valor é maior na localização do ponto e diminui com o aumento da distância, podendo chegar a zero, ou seja, valores maiores representam maior densidade do fenômeno. 
Em suma, através da análise visual e exploratória dos dados coletados destaca-se a opinião dos participantes no tocante a:

(a) manutenção e prevalência das condições de contemplação das visuais - a razão mais vezes citada para gostar dos lugares e também o uso futuro mais vezes citado;

(b) melhoria da aparência dos espaços como um todo - a razão mais vezes citada para não gostar dos lugares;

(c) uso futuro da Orla predominantemente para a contemplação das visuais, prática de esportes, lazer passivo e usufruto de bares e restaurantes;

(d) acesso exclusivo de pedestres em pontos em que hoje é permitido o acesso de veículos, tais como: Anfiteatro Pôr-do-Sol e Parque Maurício Sirotsky Sobrinho;

(e) ampliação dos caminhos para pedestres e das faixas exclusivas para ciclistas por toda a extensão da Orla; e

(f) melhorias, principalmente, de iluminação, limpeza e manutenção, sanitários públicos e mobiliário urbano.

Assim, fica evidenciado o potencial da PPSIG para identificar as percepções dos participantes quanto a preferências, usos futuros, acessibilidade e melhorias a serem realizadas em uma situação hipotética sobre a Orla do Guaíba.

\section{Avaliação da aplicação da PPSIG}

A maioria dos participantes $(76,7 \%$ - 82 de 107) declarou que concorda totalmente $(42,1 \%$ - 45 de 107) ou concorda $(34,6 \%$ - 37 de 107) com a afirmação: "Me senti colaborando para o futuro da cidade" ao utilizar a ferramenta PPSIG (Tabela 6). O resultado é bastante expressivo, uma vez que o experimento, conforme informado aos participantes na página inicial, era um exercício acadêmico, e, portanto, provavelmente os resultados não seriam utilizados para construir o futuro da cidade na prática. Em princípio, as pessoas se sentiram colaborando para o futuro da cidade, pois o ato de marcar lugares no mapa é concreto, ou seja, o que foi marcado fica automaticamente registrado no sistema, criando um senso de propriedade sobre as contribuições produzidas, e, assim, os envolvidos se sentem responsáveis pelas decisões (STERN; GUDES; SVORAY, 2009).

Com relação à pergunta: "Em geral como você avalia este método de participação?", a expressiva maioria dos participantes (85\% - 91 de 107) avaliou a PPSIG como plenamente satisfatória $(24,3 \%$ - 26 de 107) ou satisfatória $(60,7 \%$ - 65 de 107) (Tabela 7). Também em comparação aos métodos mais convencionais de participação, a expressiva maioria dos participantes $(86,1 \%$ - 93 de 108) avaliou a ferramenta como plenamente satisfatória $(22,2 \%$ - 24 de 108) ou satisfatória (63,9\% - 69 de 108) (Tabela 7). Portanto, com base nesses resultados, pode-se afirmar que os participantes avaliaram a PPSIG como amplamente satisfatória.

Especificamente quanto a eventuais dificuldades de uso de ferramentas SIG e do mapa on-line, a expressiva maioria $(82,6 \%$ - 90 de 109) dos participantes respondeu que concorda totalmente (45,9\% - 50 de 109) ou concorda $(36,7 \%$ - 40 de 109) com a afirmação 'Consegui marcar os locais desejados no mapa com a ferramenta de pontos' (Tabela 8). Esses resultados são coincidentes com a afirmação de Brown (2012) de que o uso de pontos simplifica o mapeamento para os participantes.

Tabela 6 - Me senti colaborando para o futuro da cidade

\begin{tabular}{lcc}
\hline Me senti colaborando para o futuro da cidade & $\mathbf{N}^{\mathbf{0}}$ & $\mathbf{\%}$ \\
\hline Concordo totalmente & 45 & 42,1 \\
Concordo & 37 & 34,6 \\
Nem concordo nem discordo & 23 & 21,5 \\
Discordo & 0 & 0,0 \\
Discordo totalmente & 2 & 1,9 \\
Total de participantes & 107 & 100 \\
\hline
\end{tabular}

Nota: o universo total de participantes que avaliaram a PPSIG Orla do Guaíba é 109, mas algumas questões não foram respondidas por todos. 
Tabela 7 - Como você avalia este método em geral e comparativamente

\begin{tabular}{lcccc}
\hline & $\begin{array}{c}\text { Em geral como você avalia } \\
\text { esta ferramenta de } \\
\text { participação: }\end{array}$ & $\begin{array}{c}\text { Comparativamente aos métodos } \\
\text { participativos mais convencionais } \\
\text { como você avalia esta ferramenta: }\end{array}$ \\
\cline { 2 - 5 } & $\mathbf{N}^{\mathbf{0}}$ & $\mathbf{\%}$ & $\mathbf{N}^{\mathbf{0}}$ & \% \\
\hline Plenamente satisfatória & 26 & 24,3 & 24 & 22,2 \\
Satisfatória & 65 & 60,7 & 69 & 63,9 \\
Nem satisfatória nem insatisfatória & 13 & 12,1 & 9 & 8,3 \\
Insatisfatória & 2 & 1,9 & 6 & 5,5 \\
Plenamente insatisfatória & 1 & 0,9 & 0 & 0,0 \\
Total de participantes & 107 & 100,0 & 108 & 100,0 \\
\hline
\end{tabular}

Nota: o universo total de participantes que avaliaram a PPSIG Orla do Guaíba é 109, mas algumas questões não foram respondidas por todos.

Com relação à afirmação "Consegui marcar os locais desejados no mapa com a ferramenta de linhas", ainda que a maioria $(71 \%$ - 76 de 107) dos participantes concorde totalmente $(38,3 \%-41$ de 107) ou concorde $(32,7 \%$ - 35 de 107), esses percentuais são inferiores àqueles que revelam a concordância com a capacidade de utilização da ferramenta de pontos (Tabela 8). O resultado explica-se pelo fato de que desenhar linhas requer uma capacidade motora mais aguçada do que marcar pontos. Além disso, houve dificuldades no uso do zoom em conjunto com a ferramenta de linhas. No teste piloto do experimento PPSIG Orla do Guaíba, um usuário manifestou essa dificuldade afirmando que: "Marcar pontos ok, mas para marcar linhas é um pouco mais difícil para usar o zoom e o pan.”. Ele esclareceu que não conseguiu desenhar linhas e ao mesmo tempo arrastar o mapa com o pan ou mudar o zoom, ou seja, teve que deixar o nível de zoom fixo na área que queria desenhar as linhas. Ressalta-se que não havia orientação para o respondente sobre o uso do zoom, o que poderá ser incluído em futuras aplicações.

Similarmente, com relação à afirmação de que "Consegui usar o zoom para aproximar e afastar o mapa", 82,2\% (90 de 109) dos participantes concordam totalmente $(59,6 \%$ - 65 de 109) ou concordam $(22,9 \%$ - 25 de 109) (Tabela 8). No entanto, alguns participantes expressaram dificuldades, conforme comentários tais como:

(a) "Zoom e marcação dos locais foram meio difíceis no começo" (ID 621); e

(b) "A única dificuldade foi com o zoom. Ao escolher um item para marcar no mapa eu não conseguia usar o zoom, por isso as localizações ficaram imprecisas. Só depois que me dei conta que tinha que dar o zoom antes de selecionar o item que eu queria marcar" (ID 528).

Tabela 8 - Consegui marcar os locais desejados no mapa com a ferramenta de pontos

\begin{tabular}{lcccccc}
\hline & $\begin{array}{c}\text { Consegui marcar os } \\
\text { locais desejados no } \\
\text { mapa com a } \\
\text { ferramenta de } \\
\text { pontos }\end{array}$ & $\begin{array}{c}\text { Consegui marcar os } \\
\text { locais desejados no } \\
\text { mapa com a } \\
\text { ferramenta de } \\
\text { linhas }\end{array}$ & $\begin{array}{c}\text { Consegui usar o } \\
\text { zoom para } \\
\text { aproximar e afastar } \\
\text { o mapa }\end{array}$ \\
\cline { 2 - 7 } & $\mathbf{N}^{\mathbf{0}}$ & $\mathbf{\%}$ & $\mathbf{N}^{\mathbf{0}}$ & $\mathbf{\%}$ & $\mathbf{N}^{\mathbf{0}}$ & $\mathbf{\%}$ \\
\hline CT & 50 & 45,9 & 41 & 38,3 & 65 & 59,6 \\
C & 40 & 36,7 & 35 & 32,7 & 25 & 22,9 \\
NCND & 10 & 9,2 & 15 & 14,0 & 9 & 8,3 \\
D & 7 & 6,4 & 13 & 12,1 & 7 & 6,4 \\
DT & 2 & 1,8 & 3 & 2,8 & 3 & 2,8 \\
\hline Total de participantes & 109 & 100 & 107 & 100 & 109 & 100 \\
\hline
\end{tabular}

Nota: Legenda:

CT- Concordo totalmente;

C - Concordo;

NCND - Nem concordo nem discordo;

D - Discordo; e DT - Discordo Totalmente.

Nota: o universo total de participantes que avaliaram a PPSIG Orla do Guaíba é 109, mas algumas questões não foram respondidas por todos. 
Logo, um aperfeiçoamento no comando de zoom tornará mais fácil o uso das ferramentas de desenho de linhas. Além disso, faz-se necessário, no futuro, habilitar a funcionalidade de mudança do nível de zoom mesmo após o item a ser marcado ter sido selecionado. Em suma, conclui-se que o funcionamento técnico da ferramenta é aceitável, apesar de algumas dificuldades pontuais terem sido apontadas especificamente com relação à ferramenta de linhas e ao zoom.

\section{Conclusões}

Os resultados obtidos neste estudo evidenciam o potencial da PPSIG para identificar as percepções dos participantes quanto a preferências, usos futuros, acessibilidade e melhorias a serem realizadas no trecho da Orla do Guaíba compreendido entre a Usina do Gasômetro e a Vila, com a identificação dos lugares e de seus aspectos positivos e negativos sendo realizada de maneira eficiente. $\mathrm{O}$ fato de os dados coletados com a PPSIG armazenarem a localização espacial exata dos lugares identificados, ou seja, de estarem georreferenciados, possibilita ganho adicional para o planejamento urbano. Nesse sentido, as diretrizes gerais para a Orla do Guaíba mencionadas em estudo produzido pela PMPA (PREFEITURA..., 2003), tais como ser de livre acesso à população e proporcionar a reintegração da população ao lago, além de terem sido elaboradas unicamente a partir da visão dos técnicos/especialistas, são mais genéricas do que as indicações geradas a partir dos dados espaciais coletados com a PPSIG. A conveniência de ter os dados coletados de forma automatizada e georreferenciada otimiza e amplia a capacidade de análise, como destacado por Poplin (2012). Assim, os dados podem ser manipulados em ambientes SIG, e processados junto com outras camadas de informação que comumente compõem uma base de dados espaciais de planejamento urbano (por exemplo: dados cadastrais e socioeconômicos).

O fato de a percepção da população estar representada numa camada de informação espacial facilita a tarefa de incorporar os desejos da população desde o princípio no processo de concepção de propostas, planos e/ou projetos urbanos. A sua incorporação já nas fases iniciais facilita a aceitação das propostas pelo público, evitando que a população se oponha posteriormente a projetos nos quais ela não tenha sido consultada previamente ou informada formalmente sobre o assunto, como alertam Stern, Gudes e Svoray (2009). Além disso, a consideração dessas informações já na fase propositiva levará à criação de soluções específicas para cada comunidade local (CARVER, 2001).
Além da visualização e análise de uma variedade de informações complexas em conjunto, a espacialização da percepção da população possibilita aos planejadores a transmissão dessas informações de forma mais acessível aos colegas, tomadores de decisão, e ao público em geral na forma de mapas (VAN HERZELE; WOERKUM, 2011). Logo, os mapas gerados a partir dos dados coletados com a PPSIG também têm potencial para subsidiar posteriores debates públicos. Também cabe mencionar que a utilidade das informações coletadas com a PPSIG não é restrita apenas ao setor de planejamento urbano, porque a maioria das informações necessárias à formulação de políticas públicas contém um componente espacial (SIEBER, 2006).

A aplicação PPSIG Orla do Guaíba foi avaliada de forma bastante positiva pelos participantes, tanto de maneira geral quanto comparativamente a métodos mais tradicionais de participação, tais como as audiências e consultas públicas, que têm sido criticadas pelo fato de antagonizarem o público e o governo, polarizarem as questões em pauta, e não satisfazerem os presentes (INNES; BOOHER, 2004). Os participantes também se sentiram colaborando para o futuro da cidade ao utilizar a ferramenta PPSIG pelo fato de marcarem lugares no mapa, que é algo mais concreto do que manifestações orais, além das suas contribuições ficarem automaticamente registradas no sistema. $\mathrm{O}$ mapa também possibilita uma clara referência para os participantes, facilitando as suas manifestações de forma objetiva. Nesse sentido, o mapeamento também produz conhecimento, um diferencial importante da PPSIG em comparação aos métodos tradicionais de participação. A PPSIG, ao mostrar o território e coletar a percepção dos participantes através de registros no mapa, produz conhecimento sobre esse território, pois quando uma pessoa registra algo no mapa ela também está adquirindo conhecimento sobre o lugar e descobrindo coisas. Nesse sentido, pode-se dizer que a PPSIG tanto representa quanto produz o espaço em questão.

Adicionalmente, a avaliação positiva da PPSIG pelos participantes dá suporte para o fato de que, diferentemente dos métodos tradicionais de participação, a PPSIG, ao permitir a coleta dos dados de forma automatizada e espacializada (ou georreferenciada), facilita a quantificação das opiniões. Ainda, é extremamente difícil classificar e incorporar nas propostas, planos e/ou projetos o que se ouve nos encontros presenciais, conforme enfatizam Innes e Booher (2004). Assim, os anseios da população manifestados através da PPSIG apresentam maior clareza e, logo, maior potencial para serem incorporados no planejamento urbano do que aquelas aspirações 
conhecidas através de métodos tradicionais, atributo este da PPSIG já mencionado por Poplin (2012).

Por fim, quanto a eventuais dificuldades de uso de ferramentas SIG os resultados evidenciam que os participantes, de modo geral, não encontram maiores dificuldades ao usar uma ferramenta participativa que faça uso de mapas on-line interativos e ferramentas SIG, como a PPSIG. A grande maioria conseguiu entender as perguntas e marcar os locais desejados no mapa com a ferramenta de pontos com facilidade, e, mesmo que em menor grau, desenhar linhas e utilizar o zoom satisfatoriamente. Os resultados também indicam que a ferramenta para desenhar linhas é mais trabalhosa, ao passo que a ferramenta para marcar pontos é mais fácil de usar. Esse resultado corrobora a afirmação de Brown (2012) de que o uso de pontos simplifica o mapeamento para os participantes. Logo, a ferramenta de pontos deve ser preferida, sempre que possível. Concluindo, mesmo que ainda haja, na prática, barreiras para se trabalhar em colaboração com a população, esta pesquisa demonstrou que novas metodologias, que tirem partido das TIC e dos SIG, tais como a PPSIG, podem contribuir de forma efetiva para os processos participativos e, logo, para vir a qualificar tal planejamento e a tornar as cidades mais responsivas aos seus usuários.

\section{Referências}

BATTY, M. et al. Smart Cities of the Future. UCL Working Papers, v. 188, oct. 2012.

BATTY, M. et al. Map Mashups, Web 2.0 and the GIS Revolution. Annals of GIS, v. 16, n. 1, p. 113, 2010.

BRABHAM, D. C. Crowdsourcing the Public Participation Process for Planning Projects.

Planning Theory, v. 8, n. 3, p. 242-262, 2009.

BRASIL. Lei n. 10.257, de 10 de Julho de 2001, que regulamenta os arts. 182 e 183 da Constituição Federal, estabelece diretrizes gerais da política urbana e dá outras providências. Disponível em: <http://www.planalto.gov.br/ccivil_03/leis/leis_20 01/110257.htm>. Acesso em: 4 set. 2014.

BROVELLI, M. A.; MINGHINI, M.; ZAMBONI, G. Public Participation GIS: a FOSS architecture enabling field-data collection. International Journal of Digital Earth, p. 1-19, 2014.

BROWN, G. Public Participation GIS (PPGIS) for Regional and Environmental Planning: reflections on a decade of empirical research. URISA journal, v. 25, n. 2, p. 7-18, 2012.
BROWN, G.; KYTTÄ, M. Key issues and Research Priorities for Participatory GIS: a review and synthesis based on empirical research. Applied Geography, v. 46, p. 122-136, 2014. BUGS, G. Tecnologias da Informação e Comunicação, Sistemas de Informação Geográfica e a Participação Pública no Planejamento Urbano. Porto Alegre, 2014. Tese (Doutorado em Engenharia Civil) - Escola de Engenharia, Universidade Federal do Rio Grande do Sul, Porto Alegre, 2014.

CÂMARA, G. et al. Análise Espacial e Geoprocessamento. Análise Espacial de Dados Geográficos, v. 2, 2002. Disponível em: <www.dpi.inpe.br/gilberto/livro/analise/cap1intro.pdf>. Acesso em: 4 set. 2014.

CARVER, S. Participation and Geographical Information: a position paper. In: EUROPEAN SCIENCE FOUNDATION WORKSHOP, Spoleto, 2001. Proceedigns... Spoleto, 2001.

CASTELLS, M. The Rise of the Network Society: the information age: Economy, society, and culture. New Jersey: Wiley-Blackwell, 1996.

CIDADE DEMOCRÁTICA. [Cidade]. 2013.

Disponível em: <www.cidadedemocratica.org.br>. Acesso em: 19 set. 2013.

DÁVILA, S. Internet Prepara-se Para Era da Web 3.0, Com Buscas Avançadas. Folha de S. Paulo, 21 de fev. 2007. Disponível em:

<www1.folha.uol.com.br/folha/informatica/ult124 u21656.shtml>. Acesso em: 11 ago. 2014.

DI FELICE, M. As Formas Digitais do Social e os Novos Dinamismos da Sociabilidade Contemporânea. In: RELAÇÕES Públicas Comunitárias: a comunicação em uma perspectiva dialógica e transformadora. São Paulo: Summus, 2007.

DRAGIĆEVIĆ, S.; BALRAM, S. A Web GIS Collaborative Framework to Structure and Manage Distributed Planning Processes. Journal of Geographical Systems, v. 6, n. 2, p. 133-153, 2004.

FEDOZZI, L. et al. Orçamento Participativo de Porto Alegre: perfil, avaliação e percepções do público participante. Porto Alegre: Gráfica e Editora Hartmnn, 2013.

FORESTER, J. Making Participation Work When Interests Conflict: moving from facilitating dialogue and moderating debate to mediating negotiations. Journal of the American Planning Association, v. 72, n. 4, p. 447-456, 2006. 
HALL, G. B. et al. Community-Based Production of Geographic Information Using Open Source Software and Web 2.0. International Journal of Geographical Information Science, v. 24, n. 5, p. 761-781, 2010.

HALLER, C.; HÖFFKEN, S. New

Communication Tools and eParticipation: social media in urban planning. In: SCHRENK, M.; POPOVICH, V.; ZEILE, P. (Eds.). REALCORP 2010 15TH INTERNATIONAL CONFERENCE, Vienna, 2010. Proceedings... Vienna, 2010.

HUDSON-SMITH, A.; CROOKS, A. The Renaissance of Geographic Information: neogeography, gaming and Second Life. UCL Working Papers, v. 142, 2008.

INNES, J. E.; BOOHER, D. E. Reframing Public Participation: strategies for the 21st century.

Planning Theory \& Practice, v. 5, n. 4, p. 419436, 2004.

KAHILA, M. Possibilities of Web-Based SoftGIS Method in Revealing Residents Evaluation Knowledge of the Living Environment. In: FUTURE - FUTURE URBAN RESEARCH IN EUROPE, THE ELECTRONIC CITY CONFERENCE, Bratislava, 2008. Proceedings... Bratislava, 2008.

KAHILA, M.; KYTTÄ, M. SoftGIS as a BridgeBuilder in Collaborative Urban Planning. In: PLANNING Support Systems Best Practice and New Methods. Springer: Netherlands, 2009.

KINGSTON, R. Online Public Participation GIS for Spatial Planning. In: NYERGES, T.; COUCLELIS, H.; MCMASTER, R (Eds.). The SAGE handbook of GIS and society. London: Sage Publications, 2011.

LÉVY, P. As Tecnologias da Inteligência: o futuro do pensamento na era da informática. Rio de Janeiro: Editora 34, 1993.

MAPTIONNAIRE. [Maptionnaire]. 2014. Disponível em: <mapita.eu/en>. Acesso em: 18 jul. 2014.

MINISTÉRIO DAS COMUNICAÇÕES.

Smartphone Ficará até 30\% Mais Barato. 2013. Disponível em: <http://www.mc.gov.br/sala-deimprensa/todas-as-noticias/institucionais/26679smartphone-ficara-ate-30-mais-barato>. Acesso em: 20 ago. 2014.

NYERGES, T. et al. Collaborative Water Resource Decision Support: results of a field experiment. In: Annals of the Association of American Geographers, v. 96, n. 4, p. 699-725, 2006.
O'REILLY, T. What is Web 2.0: design patterns and business models for the next generation of software. Communications \& strategies, v. 1, p. 17, 2007.

PEREIRA, G.; FLORENTINO, P. V.; ROCHA, M. C. F. City as a Social Network-Brazilian Examples. In: Urban and Regional Data Management: UDMS Annual. 2013.

PREFEITURA MUNICIPAL DE PORTO ALEGRE. Diretrizes Urbanísticas Para a Orla do Guaíba no Município de Porto Alegre. PMPA, 2003. Disponível em: $<$ http://lproweb.procempa.com.br/pmpa/prefpoa/sp m/usu_doc/projeto_Orla7.pdf $>$. Acesso em: 29 maio 2014.

POPLIN, A. Web-Based PPGIS for Wilhelmsburg, Germany: an integration of interactive GIS-based maps with an online questionnaire. URISA journal, v. 25, n. 2, p. 71-84, 2012.

ROCHA, M. C. F.; PEREIRA, G. C. Mídias Sociais e Espaços de Participação. In: SIMPÓSIO DE PESQUISA EM TECNOLOGIAS DIGITAIS E SOCIABILIDADE: MÍDIAS SOCIAIS, SABERES E REPRESENTAÇÕES, Salvador, 2011. Anais... Salvador, 2011.

SIEBER R. E. Public Participation and Geographic Information Systems: a literature review and framework. Annals of the American Association of Geographers, v. 96 n. 3, p. 491-507, 2006.

SOS MATA ATLÂNTICA. [Mapas]. Disponível em: <http://mapas.sosma.org.br/>. Acesso em: 4 jul. 2015.

STERN, E.; GUDES, O.; SVORAY, T. WebBased and Traditional Public Participation in Comprehensive Planning: a comparative study. Environment and planning B, v. 36, n. 6, p. 1067-1085, 2009.

VAN HERZELE, A.; Van WOERKUM, C. On the Argumentative Work of Map-Based Visualisation. Landscape and Urban Planning, v. 100, n. 4, p. 396-399, 2011.

VILLAÇA, F. As Ilusões do Plano Diretor. São Paulo: 2005.

WALLIN, S.; HORELLI, L. Playing With the Glocal Through Participatory e-Planning. The Journal of Community Informatics, v. 6, n. 3, 2012. 
Geisa Tamara Bugs

Instituto de Ciências Exatas e Tecnológicas, Curso de Arquitetura e Urbanismo | Universidade Feevale | ERS-239, 2755 | Novo Hamburgo RS - Brasil | CEP 93525-075 | Tel.: (51) 3586-8800 | E-mail: geisabugs@gmail.com

\section{Antônio Tarcísio da Luz Reis}

Departamento de Arquitetura, Faculdade de Arquitetura | Universidade Federal do Rio Grande do Sul | Rua Sarmento Leite, 320 , Centro | Porto Alegre - RS - Brasil | CEP 90050-170 | Tel.: (51) 3308-4529 | E-mail: tarcisio.reis@ufrgs.br

\section{Revista Ambiente Construído}

Associação Nacional de Tecnologia do Ambiente Construído

Av. Osvaldo Aranha, $99-3^{\circ}$ andar, Centro

Porto Alegre - RS - Brasil

CEP $90035-190$

Telefone: +55 (51) 3308-4084

Fax: +55 (51) 3308-4054

www.seer.ufrgs.br/ambienteconstruido

E-mail: ambienteconstruido@ufrgs.br

142 Bugs, G. T.; Reis, A. T. 